Journal of Animal and Veterinary Advances 11 (12): 2054-2058, 2012

ISSN: $1680-5593$

(C) Medwell Journals, 2012

\title{
Development of Hydronephrosis Inbred Strain Mouse, ICR/Mlac-Hydro
}

\author{
${ }^{1}$ Kanchana Kengkoom, ${ }^{1}$ Khin Maeung Zaw, ${ }^{2}$ Rapee Inpunkaew, ${ }^{1}$ Wannee Angkhasirisap, \\ ${ }^{2}$ Pravate Thongsiri and ${ }^{3}$ Sumate Ampawong \\ ${ }^{1}$ Academic Service Office, ${ }^{2}$ Quality Assurance Office, ${ }^{3}$ Veterinary Medical Care Office, \\ National Laboratory Animal Center, Mahidol University, Bangkok, Thailand
}

\begin{abstract}
Hydronephrosis was accidentally observed when autopsied the out bred ICR mice in routine health monitoring program. Previously, a low incidence of mild hydronephrosis was observed mostly in male mice and found only on the right kidney. Selective inbreeding of this mutant led us to the establishment of a colony of inbred hydronephrosis mice. After inbreeding for 20 generations, a surprisingly high incidence of hydronephrosis was encountered and we finally obtained a strain of mice with a very high incidence of severe hydronephrosis affected on both sides of kidney and in both sexes as the process of inbreeding has been increased. Phenotypes determination, genetic segregation test crosses and histological study of kidneys were also performed.
\end{abstract}

Key words: Hereditary hydronephrosis, kidney disease, development of inbred mouse strain, autosomal recessive gene, pathological characteristic

\section{INTRODUCTION}

Hydronephrosis (HN) has been defined by many investigators as distension of the renal pelvis, renal calyces and diverticula of varying degrees. It can also be determined by a gross lesion of the kidneys. The dilatation of the pelvis and calyces was readily apparent on histopathological examination with atrophy of the renal parenchyma secondary to obstruction the urine outflow in most animals.

Observation of $\mathrm{HN}$ in laboratory mice has long been reported elsewhere for many years ago. Some have described strains of rats with unilateral right $\mathrm{HN}$ (Astarabadi and Bell, 1962; Sellers et al., 1960) whereas others have reported variably right or left side unilateral $\mathrm{HN}$ or bilateral HN (Warner, 1971; Lozzio et al., 1972). HN in STR N inbred strain mice (Silverstein et al., 1961), NZC inbred mice (Warner, 1971; Collins et al., 1972), DDD inbred mice (Nakajima et al., 1983), C57BL/KsJ inbred mice (Lamont, 1991) and C57BL/MsNrs inbred mice (Takano et al., 1973) were also reported. Almost of these strains are spontaneously mutation originate from inbred mice.

Since, researchers have been observed spontaneous $\mathrm{HN}$ in the ICR outbred mouse stock in routine health monitoring program. Researchers aim to develop a colony of inbred mice with congenital, persistant, bilateral $\mathrm{HN}$ suitable for such biomedical science studies by selective inbreeding for 20 generations. Subsequently, we purposed the lesion in this colony has been stable over several generations of inbreeding with a very high incidence of $\mathrm{HN}$ kidneys. Phenotypes determination, genetic segregation test crosses and histological study of kidneys were also performed.

\section{MATERIALS AND METHODS}

Housing: The animals were maintained in a clean conventional room. The room temperature was maintained at $22 \pm 2^{\circ} \mathrm{C}$ by air-conditioners. A cycle of $12 \mathrm{~h}$ artificial light and $12 \mathrm{~h}$ of darkness was maintained. Mice were housed in polycarbonate cages. The animals were fed ad libitum and provided a commercial mouse pellet diet and chlorinated water. The wood-shaving was used as bedding and were autoclaved before used. Animal studies were in agreement with Mahidol University policy for the care and use of animals for scientific purposes and approved by the institutional committee on ethics.

Method of inbreeding: The colony was initially started from 10 pairs of ICR outbred mice. All pups of first litter were killed and autopsied for observed affected kidneys. The pups from the second litter of the pairs which produced some hydronephrotic pups in their previous litters were used as the breeders for the first generation, beginning with brother and sister full-sib mating program.

Corresponding Author: Kanchana Kengkoom, Academic Service Office, National Laboratory Animal Center, Mahidol University, Bangkok, Thailand 
In further subsequent generations, mating always conducted with the pups from the second litters after confirming the presence of $\mathrm{HN}$ among the pups of their first litter.

Autopsy: $\mathrm{HN}$ has been defined by many investigators as dilated renal pelvis and calyces of varying degree. $\mathrm{HN}$ can be determined by a longitudinal section of the kidneys in autopsy program. The dilatation of the pelvo-calyceal system was readily apparent on this cut section.

Histological studies: Longitudinal sections of normal, mild and the severe type hydronephrotic kidneys were fixed in buffered formalin. These specimens were embedded in paraffin, sectioned at $4 \mu$. The slides were stained with Hematoxylin and Eosin ( $\mathrm{H}$ and $\mathrm{E})$.

Grading of hydronephrosis: The degree of $\mathrm{HN}$ was scored as normal, mild and severe. Cases ranged from complete absence of $\mathrm{HN}$ (normal) through, varying degrees of pelvic dilation ranging from a suspicion mild to severe $\mathrm{HN}$.

The affected kidneys had been phenotyped and scored for $\mathrm{HN}$ severity by defined as degree of renal pelvic dilation. In mild hydronephrotic kidneys, the swelling size of kidney was not very apparent but a dilatation of pelvocalyceal region was presence.

In extreme cases, swelling kidneys were usually marked and varying in size according to the degree of severity, the urine like fluid was replaced in the areas of grossly loss tissue. The fluid was spilling out from the swelling kidney when a cut section was made and the kidney was collapsed down due to the great loss of supporting tissues. In some severe cases, almost all tissues were loss and left the kidney as a transparent sac filled with yellow colored fluid (Fig. 1).

Phenotyping: Phenotypes determination for the Gpi-1, Trf, Es-1, Mup-1 and Hbb loci was carried out by using cellulose acetate electrophoresis (Hoffman, 1984).

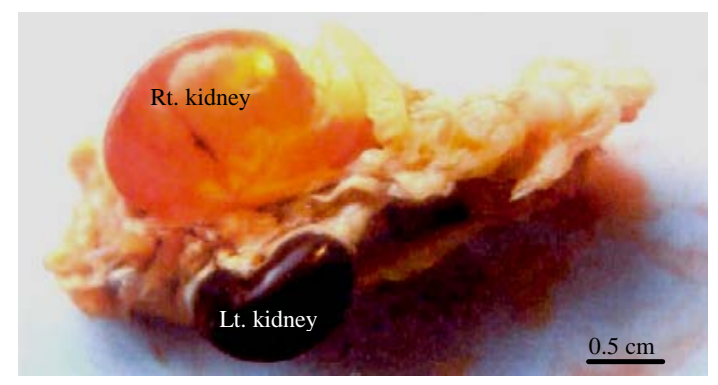

Fig. 1: Hydronephrosis in extremely case, macroscopically
Segregation: Genetic segregation tests were done between crosses $\mathrm{HN}$ inbred mice (F20) and free HN ICR inbred mice (F20) inter-crosses between F1 mice of the two parental strains and reciprocal back-crosses between F1 mice and their two parental strains mice.

Statistical analysis: ANOVA was used as a tool to detect the differentiation of quantitative variable among generation at the significance level of $\mathrm{p}<0.05$.

\section{RESULTS AND DISCUSSION}

Incidence of hydronephrosis: Incidence of $\mathrm{HN}$ and inbreeding performances of $\mathrm{HN}$ mice through completion of inbreeding process from F0-F20. A direct relationship was observed between severity and incidence of $\mathrm{HN}$ and inbreeding process because $\%$ of $\mathrm{HN}$ in males and females, overall $\% \mathrm{HN}$ in both sexes and on both kidneys were relatively increased as generation of inbreeding increased. But in contrast to this, the average litter size of the animals was decreased in later generations (from 13-8) due to inbreeding process. In addition, Table 1 shows that incidence of $\mathrm{HN}$ increased significantly with generation increased gradually in $\%$ of incidence of both sexes, overall incidence and in $\%$ incidence in both kidneys.

Histological findings: Histological findings were shown in Fig. 2. The pelvocalyceal region was found dilated in both mild and severe type hydronephrotic kidneys. In most severe cases, the papillary tissues became atrophy and were hanging in the lumen of dilated pelvis area. Gross tissues were loss in medulla and the urine like fluid replaced in these areas. The trapped-fluid compressed the medulla tissues and may causes renal tubules collapsed. The trapped fluid in pelvis region also changed the appearances of kidney shape largely distended and swelling.

\section{Phenotyping}

Determination of phenotypes: Phenotypes for Gpi- 1 , Trf, Es-1, Mup-1 and Hbb loci of two inbred mouse strains, $\mathrm{HN}$ and Free-HN (F20-21) were determination by cellulose acetate electrophoresis. The electrophoresis was carried out in two inbred mice strains, $\mathrm{HN}$ and Non-HN strain of F20-21 in 5 loci. Both of these inbred lines were originally derived from outbred ICR strain mice. The two lines were separated into hydronephrotic and free-hydronephrotic lines since, early generations. Selective inbreeding program was started in the late 1992. They were in F20-21 generations by the time this electrophoresis was done. Among the tested loci, a polymorphism found in Gpi-1 
Table 1: Incidence of hydronephrosis mice among 0-20 generation

\begin{tabular}{lcccccc}
\hline Gen $(\mathrm{F})$ & Av. Lit. size & HN in male $(\%)$ & HN in female $(\%)$ & Overall \% HN & HN on right (\%) & HN on both (\%) \\
\hline $0-4$ & $12.000^{1-3}$ & $73.400^{1}$ & $26.800^{1}$ & $39.600^{1}$ & $87.000^{1-3}$ & $13.000^{1-3}$ \\
$5-9$ & $7.600^{1}$ & 82.000 & $55.400^{2}$ & $43.600^{2}$ & $49.000^{1}$ & $51.200^{1}$ \\
$10-15$ & $7.800^{2}$ & 84.700 & $56.200^{3}$ & 73.200 & $35.000^{2}$ & $65.200^{2}$ \\
$16-20$ & $7.800^{3}$ & $99.000^{1}$ & $88.400^{1-3}$ & $93.800^{1,2}$ & $36.000^{3}$ & $64.000^{3}$ \\
ANOVA p-value & 0.015 & 0.045 & 0.010 & 0.000 & 0.002 & 0.008 \\
\hline
\end{tabular}

Gen (F): Generation, Av. Lit. size: Average Litter size; HN: Hydronephrosis, ${ }^{1.3}$ Significance match paired

Table 2: Genetic test crossings for hy dronephrosis gene

\begin{tabular}{|c|c|c|c|c|c|}
\hline Type of crossing $\mathrm{HN}$ & No. of cross & No. of born & Av. Lit. size & No. with animal $\mathrm{HN}$ & Percentage \\
\hline \multicolumn{6}{|l|}{ Parental crosses (hn/hn $\mathbf{x}+/+)$} \\
\hline Male $\mathrm{HN}(\mathrm{F} 19) \times$ Female free $\mathrm{HN}$ & 4 & $56(\mathrm{~F} 1)$ & 14.0 & $0 / 56$ & 0.0 \\
\hline Male $\mathrm{HN}(\mathrm{F} 18) \times$ Female free $\mathrm{HN}$ & 3 & $36(\mathrm{~F} 1)$ & 12.0 & $0 / 36$ & 0.0 \\
\hline \multicolumn{6}{|l|}{ Inter crosses $(h n /+x$ hn/ +$)$} \\
\hline $\mathrm{F} 1 \times \mathrm{F} 1$ & 12 & 133 & 15.5 & $25 / 133$ & 18.7 \\
\hline \multicolumn{6}{|c|}{ Reciprocal Back Crosses (B/C) (Parental $\times$ F1) $(\mathrm{B} / \mathrm{C}(1)+/+\mathrm{x}$ hn/ + ) } \\
\hline Male free $\mathrm{HN}$ x Female F1 & 4 & 18 & 72.0 & $0 / 72$ & 0.0 \\
\hline Female free $\mathrm{HN} \times$ Male F1 & 9 & 11.8 & 87.0 & $0 / 87$ & 0.0 \\
\hline \multicolumn{6}{|l|}{$\mathrm{B} / \mathrm{C}$ ( 2) hn/hn $\times$ hn/ +} \\
\hline Male HN x Female F1 & 10 & 10.0 & 100.0 & $36 / 100$ & 36.0 \\
\hline Female HN x Male F1 & 12 & 10.3 & 118.0 & $61 / 118$ & 51.7 \\
\hline
\end{tabular}

Av. Lit. size: Average Litter size, $\mathrm{HN}$ and hn: Hydronephrosis
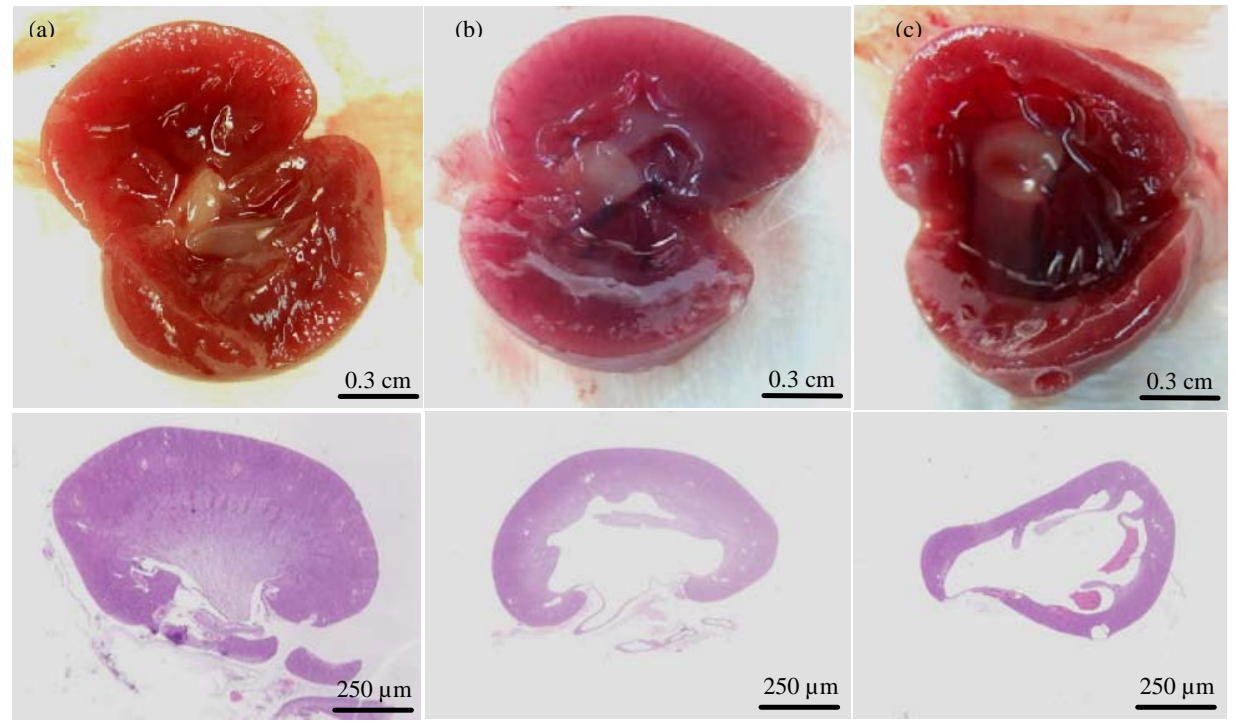

Fig. 2: Severity grading of hydronephrosis (mild to severe) and intact kidney, macroscopically and microscopically with $\mathrm{H}$ and $\mathrm{E}$ stained; a) In normal kidney, a normal texture of renal tubules is found at papillary region; b) In mild type hydronephrosis kidney, tissues lost are found at papillary and renal pelvis areas. Renal fluid in the enlarge region are trapped and cause the pelvocalyceal dilatation and made tubules collapsed; c) In severe type of hydronephrosis kidney, grossly loss of medullary and papillary tissue was observed. Trapped fluid made the tubules and tissues compressed with flattened epithelia and the appearance of kidney largely distended

locus between the two strains as Gpi-1 a for $\mathrm{HN}$ strain and $\mathrm{b}$ for Free-HN strain but the rest were similar to its original ICR mice.

Genetic test crosses: Genetic test cross was shown in Table 2. Reciprocal crosses between two parental strains, $\mathrm{HN}$ inbred (F19) and Free-HN inbred strain (F18) were mated. Among $72 \mathrm{~F} 1$ weaning from these crosses, none was found hydronephrotic kidney. In F 1 intercrosses, out of 133 weaning of these crosses, $25(18.79 \%)$ were found positive $\mathrm{HN}$ in their kidneys. In reciprocal back-crosses between F1 animals and Free-HN parental strain mice, a total of 159 animals produced, none of them were found hydronephrotic kidney.

The other reciprocal back-crosses between F1 mice and $\mathrm{HN}$ parental mice, a considerable number of mice with hydronephrotic kidneys were observed. Back-crosses between hydronephrotic male mice (F20) and the female 
mice from F1 group, produced 36.0\% (36/100) while back-crosses between hydronephrotic female mice (F20) and male mice from $F 1$, produced $51.75 \%(61 / 118)$.

Unilateral or bilateral $\mathrm{HN}$ is a relatively common finding in laboratory mice. It is usually regarded as an incidental finding, particulary if only 1 kidney is involved (Percy and Barthold, 2001). Previously, before ICR mice have been inbreeding, mild type $\mathrm{HN}$ were mostly observed on the right side kidneys in male mice. Rarely found in both kidneys or on left kidney alone or in female mice. After inbreeding, more percent of severely affected kidneys were observed and more incidence of both side affected kidneys in both sexes were also increased in the later generations. By this evidence, there is a marked relationship between the incidence and severity of $\mathrm{HN}$ and subsequent inbreeding process. Completion of 20 generations ( $\mathrm{F} 20$ ), took about 5 years.

$\mathrm{HN}$ of the mice can be classified as an open hydronephrotic type which is the more common form contrast to obstructive type (Wallace and Spickett, 1967) because of unable to find the definite cause such as malformation of skeletal system and the obstructions along the urinary tract, especially indicated by hydroureter. Both sides of the kidney gradually developed hydronephrosis, there for the severity of lesion depended on age. By this reason, the affected animals showed no clinical abnormal signs because of the remaining renal reserve function. Similar to $\mathrm{MRC} / \mathrm{H}$ rats, an autosomal dominant trait for the bilirubin glucuronyl transferase deficiency (Lozzio et al., 1972), notwithstanding the severity of renal damage, like that seen in animals with severe bilateral $\mathrm{HN}$, the rat survive, grow and reproduce in obviously healthy condition.

The phenotyping indicated the difference of $a$ and $b$ on Gpi-1 loci between two inbred mouse strains. Since, Gpi-1, Glucose phosphate isomerase 1 (multifunctional protein), act in the development of somatosensory and motoric neural structure (Repiso et al., 2008). Unfortunately there is no report the association between Gpi-1 and $\mathrm{HN}$, unless Gpi deficiency related to nonspherocytic hemolytic anemia in human (Beulteret al., 1997) and neurological impairment (Repiso et al., 2008). However, this polymorphism could be useful for a Marker gene among the two strains in future genetic identification.

Genetic test cross revealed that the gene controlled the $\mathrm{HN}$ model is a recessive gene and gene interaction between $\mathrm{HN}$ and free $\mathrm{HN}$ animals is followed the Mendalian's trait of inheritation with the true expected values. Researchers therefore, concluded a bilateral HN-bearing ICR mice which are recessively inherited have been established by full-sibling mating. Several mouse $\mathrm{HN}$ models related to recessive gene have been reported and suggested that phenotype trait was controlled by polygenes, e.g., Bone morphogenetic protein (B mp4) (Miyazaki et al., 2000), Glial Derived Neurotrophic Factor (GDNF) and ret-K (Schuchardt et al., 1996), murine forkhead/winged helix gene (Kume et al., 2000) and Pax-2 (Favor et al., 1996) moreover with some effect of hormone, e.g., sex hormone and rennin angiotensin system, etc. (Goto et al., 1984; Horton et al., 1988; Susic et al., 1975; Tauchi and Kanehara, 1996; McDill et al., 2006).

Generally, there are three types of experimental animal models for fetal renal disease including $\mathrm{HN}$, base on spontaneous mutation, surgical model and knockout model (Peter, 2001). Hereditary and spontaneous mutation has been described in many strain, e.g., STR/N, NZC, C3H, C57BL, DDD and cph, mice (Cohen et al., 1970; Nakajima et al., 1983; Goto et al., 1984; Horton et al., 1988). Some of these models including the mice therefore raise the question of whether the appearance of $\mathrm{HN}$ may occur without a hydrodynamic obstruction. Although, this model has not been yet describes as showing spontaneous resolution as seen in the human, researchers yet consider that this inbred strain of $\mathrm{HN}$ mice would be a useful animal model for the urologists, pathologists, especially for the study of experimantal $\mathrm{HN}$. At least advantage of this model is its mechanistic precision and the ability to manipulate it's functionally that gradually developed in human being.

\section{CONCLUSION}

The results indicated that autosomal recessive gene controlled the inheritance of these non obstruction type hydronephrosis mice. In all cases did not appear to have had a marked effect on survival. These mice may accordingly be a suitable laboratory animal model in which to further explore the detailed process whereby this condition might be shared some pathological characteristic between man and animals.

\section{REFERENCES}

Astarabadi, T. and E.T. Bell, 1962. Spontaneous hydronephrosis in albino rats. Nature, 195: 392-393.

Beulter, E., C. West, H.A. Britton, J. Harris and L. Forman, 1997. GlucosePhosphate Isomerase (GPI) deficiency mutations associated with Hereditary Nonspherocytic Hemolytic Anemia (HNSHA). Blood Cells Mol. Dis., 23: 402-409.

Cohen, B.J., De R.W. Bruin and W.J. Kort, 1970. Heritable hydronephrosis in a mutant strain of Brown Norway rats. Lab. Anim. Care., 20: 489-493.

Collins, G.R., C.R. Goodheart and D. Henson, 1972. Spontaneous heritable hydronephrosis in inbred mice. 1. Description, incidence and distribution of lesions. Lab. Anim. Sci., 22: 333-338. 
Favor, J., R. Sandulache, A. Neuhauser-Klaus, W. Pretsch, B. Chatterjee and E. Senft, 1996. The mouse Pax2 (1Neu) mutation is identical to a human PAX2 mutation in a family with renal-coloboma syndrome and results in developmental defects of the brain, ear, eye and kidney. Proc. Natl. Acad. Sci. USA., 93: 13870-13875.

Goto, N., Y. Nakajima, T. Onodera and K. Imamura, 1984. Inheritance of hydronephrosis in the mouse strain DDD. Lab. Anim., 18: 22-25.

Hoffman, H.A., 1984. Qualitative Characters in Genetic Monitoring. In: ICLAS Manual for Genetic Monitoring of Inbred Mice, Nomura, T., K. Esaki and T. Tomita (Eds.). University of Tokyo Press, Tokyo, Japan, pp: 26-113.

Horton Jr., C.E., M.T. Davisson, J.B. Jacobs, G.T. Bernstein and A.B. Retik, 1988. Congenital progressive hydronephrosis in mice: A new recessive mutation. J. Urol., 140: 1310-1315.

Kume, T., K. Deng and B.L. Hogan, 2000. Murine forkhead/winged helix genes Foxc1 (Mf1) and Foxc2 (Mfhl) are required for the early organogenesis of the kidney and urinary tract. Development, 127: $1387-1395$.

Lamont, G.W., 1991. Hereditary hydronephrosis in C57BUKs J mice. Lab. Anim. Sci., 41: 312-312.

Lozzio, B.B., E. Buonocure and D. Kentera, 1972. Radiologic and functional studies in rats with hereditary hydronephrosis. Invest. Urol., 10: 84-87.

McDill, B.W., S.Z. Li, P.A. Kovach, L. Ding and F. Chen, 2006. Congenital pregressive hydronephrosis (cph) is caused by an S256 mutation in AQP-2 that affects its phosphorylation and apical membrane accumulation. Proc. Natl. Acad. Sci. USA., 103: 6952-6957.

Miyazaki, Y., K. Oshima, A. Fogo, B.L. Hogan and I. Ichikawa, 2000. Bone morphogenetic protein 4 regulates the budding site and elongation of the mouse ureter. J. Clin. Invest., 105: 863-873.
Nakajima, Y., K. Emamura, T. Onodera and N. Goto, 1983. Hydronephrosis in the inbred mouse strain ODD. Lab. Anim., 17: 143-147.

Percy, D.H. and S.W. Barthold, 2001. The Mouse. In: Pathology of Laboratory Rodents and Rabbits, Percy, D.H. and S.W. Barthold (Eds.). Iowa State University Press, USA., pp: 3-106.

Peter, C.A., 2001. Animal models of fatal renal disease. Prenat. Diagn., 21: 917-923.

Repiso, A., R. Andres, F. Climent and J.M. Urena, 2008. Expression patterns in mouse embryos of neuroleukin/glucose-6-phosphate isomerase and autocrine motility factor receptor. Anat. Histol. Embryol., 37: 380-382.

Schuchardt, A., V. D'Agati, V. Pachnis and F. Costantini, 1996. Renal agenesis and hypodysplasia in ret-kmutant mice result from defects in ureteric bud development. Development, 122: 1919-1929.

Sellers, A.L., S. Rosenfeld and N.B. Friedman, 1960. Spontaneous hydronephrosis in the rat. Proc. Soc. Exp. Biol. Med., 104: 512-515.

Silverstein, E., L. Sokotoff, O. Mickelsen and G.E. Jay, 1961. Primary polydipsia and hydronephrosis in an inbred strain of mice. Am. J. Pathol., 38: 143-159.

Susic, D., J.C. Sparks and D. Kentera, 1975. The reninangiotensin system in rats with hereditary hydronephrosis. Pflugers Arch., 358: 265-274.

Takano, K., A. Ogura, O. Suzuki, Y. Noguchi, Y. Yamamoto and T. Asano, 1973. Heredity hydronephrosis in C57UMsNrs mice. Lab. Anim., 42: 107-109.

Tauchi, K. and H. Kanehara, 1996. Hypertension and the renin-angiotensin system in the congenital hydronephrosis rat with non-obstructive pelviureteric junction abnormalities. Exp. Nephrol., 4: 60-64.

Wallace, M.E. and S.G. Spickett, 1967. Hydronephrosis in mouse, rat and man. J. Med. Genet., 4: 73-82.

Warner, N.L., 1971. Spontaneous hydronephrosis in the inbred mouse strain NZC. Aust. J. Exp. Biol. Med. Sci., 49: 477-486. 